\title{
An ultrasonic analysis of the comparative efficiency of various cardiotomy reservoirs and micropore blood filters
}

\author{
D. T. PEARSON, B. G. WATSON, AND P. S. WATERHOUSE
}

From the Regional Cardiothoracic Centre, Freeman Hospital, Newcastle upon Tyne NE7 7DN, UK

Pearson, D. T., Watson, B. G., and Waterhouse, P. S. (1978). Thorax, 33, 352-358. An ultrasonic analysis of the comparative efficiency of various cardiotomy reservoirs and micropore blood filters. The ability of 12 commercially available cardiotomy reservoirs to remove bubbles from aspirated blood was investigated by means of a simulated cardiopulmonary bypass circuit and an ultrasonic microbubble detector. Performance varied considerably. The number of gaseous microemboli remaining after passage of blood through the reservoir was reduced by (a) holding the blood in the reservoir, $(b)$ reducing the volume of air mixed with the aspirated blood, and $(c)$ using a reservoir that did not induce turbulence and that contained integral micropore filtration material. Further micropore filtration of the blood after passage through the cardiotomy reservoir was beneficial, and significantly more bubbles were extracted when the microfilter was sited below the reservoir than when it was placed in the arterial line.

Several investigators have described the deleterious effects resulting from the functional replacement of the heart and lungs by a pump oxygenator during open-heart surgery (Aguilar et al., 1971; Brennan et al., 1971; Aberg, 1974; Branthwaite, 1975; Aberg and Kihlgren, 1977). As well as disturbances produced by systemic arterial hypotension (Tufo et al., 1970) and non-pulsatile flow (Wright and Sanderson, 1972), the significant part played by microemboli in altering cerebral physiology is well documented (Patterson and Kessler, 1969; Solis et al., 1974; Lancet, 1975). Emboli of fat, silicone, aggregates in stored blood, calcium, and gas have been implicated in the widespread organ dysfunction that can occur. Improvement in oxygenator design and perfusion technique can reduce the number of microemboli during surgery (Karlson et al., 1974; Siderys et al., 1975). Cardiotomy suction, however, is an important source of gaseous microemboli even when clinically acceptable cardiotomy reservoirs are used (Gallagher and Pearson, 1973; Solis et al., 1976).

The extended duration of cardiopulmonary bypass for open-heart surgery requires the aspiration of intracardiac blood and its return to the extracorporeal circuit. The volume of this blood varies considerably, depending on factors such as aortic clamping, type of cardiac defect, and the presence of bronchial or other extracardiac collateral flow Most oxygenators in common use alter the bloof in a manner that is detrimental to the tissues being perfused (Loop et al., 1976), and these effects are exaggerated after blood has been aspirated from the heart with resultant red cell destruction and the formation of gas and particulate emboli. Most cardiotomy reservoirs contain a defoaming sub $\underline{\Xi}$. stance and filters to remove these emboli. Arteriad line and cardiotomy microfiltration reduce the incidence of cerebral microemboli and reduce mortality (Hill et al., 1970; Clark and Reed, 1974)

Commercially available cardiotomy reservoirs do not completely remove all bubbles from the blood passing through them so that when cardiser otomy suction blood is returned to the oxygenatorv the number of gaseous microemboli passing alongu the arterial line to the patient is increased (Gallagher and Pearson, 1973; Loop et al., 1976) We report an assessment of the comparative efficiency of gaseous microemboli extraction by 10 cardiotomy reservoirs and show how this can be improved by further microfiltration.

\section{Methods and materials}

An in-vitro cardiopulmonary bypass circuit was. constructed as shown in Fig. 1. The main circui 


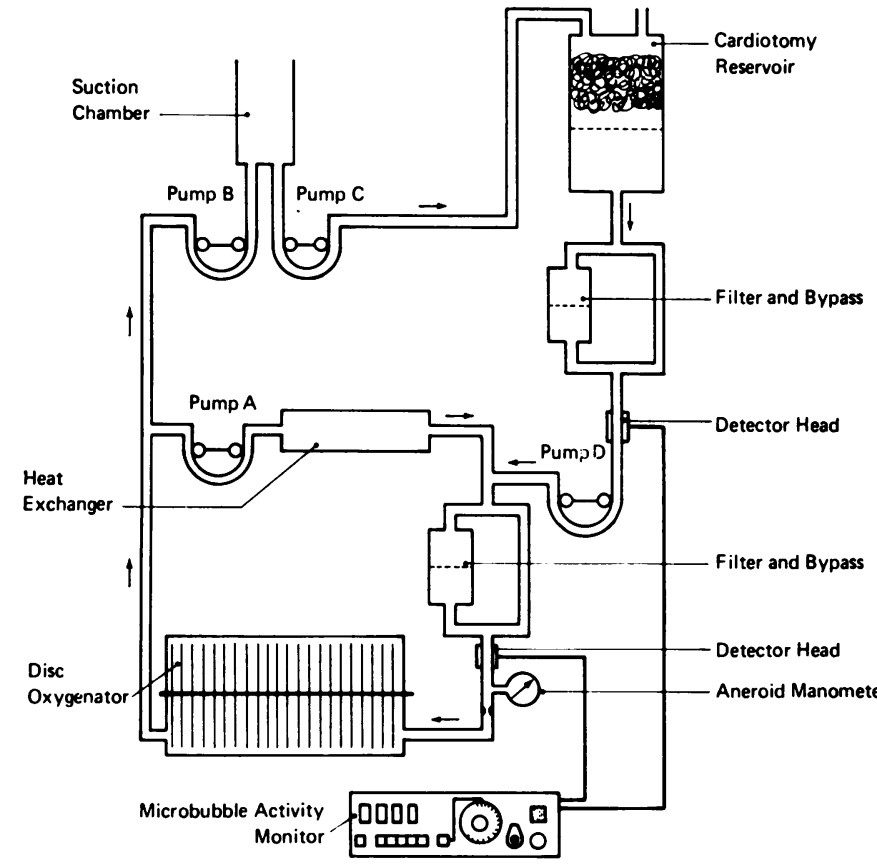

Fig. 1 Schematic diagram of in-vitro cardiopulmonary bypass circuit (see text).

consisted of a polycarbonate disc oxygenator with the arterial and venous connections joined by a loop of $\frac{3}{8}$-inch diameter polyvinyl chloride tubing. The circuit was primed with heparinised acidcitrate-dextrose blood, which was then circulated at a constant flow rate of $2.51 / \mathrm{min}$ by a double arm non-pulsatile roller pump (pump A). The temperature of the blood was maintained at $37^{\circ} \mathrm{C}$ by a heat exchanger. The detector head of the TM8 Microbubble Activity Monitor* was applied to the external surface of the circuit tubing. A continuous narrow beam of ultrasound was propagated by the transducer into the blood passing through the tubing, and as gaseous microemboli passed this beam the receiving transducer picked up modifications in the signal, which were processed by an electronic unit. The bubble counts were presented by a digital display in the size range selected on the sensitivity control. This detector position in the arterial line was used to compare the efficiency of the micropore filter in the cardiotomy return line and the micropore filter in the arterial line in removing microbubbles.

The blood was circulated without rotation of the discs in the oxygenator until the main circuit was free of gaseous microemboli. Blood was then

*Technique Laboratories, 1 High Street, Hartley Wintney, Hampshire RG27 8PE, UK. pumped at $0.51 / \mathrm{min}$ from the main circuit to the base of an open-ended jar by pump B. At the same time blood and air were aspirated from the jar by pump $\mathrm{C}$, whose flow rate could be adjusted to vary the proportion of blood and air. This mixture simulating cardiotomy suction was discharged into the cardiotomy reservoir under investigation.

When a suitable volume of blood had collected in the cardiotomy reservoir it was returned to the main circuit either directly or through a micropore filter at $0.51 / \mathrm{min}$ by pump D immediately or after a variable delay. The microbubble detector head was applied to the tubing distal to the cardiotomy reservoir, micropore filter, and bypass to assess the number and size of gaseous microemboli remaining in the blood.

Our first experiments showed that with a given cardiotomy reservoir the numbers of gaseous microemboli varied by less than $5 \%$ in successive experiments when the effluent from the reservoir was monitored. This consistency enabled us to compare the efficiency of microbubble extraction of different types of cardiotomy reservoir and to measure the further improvement produced by microfiltration either immediately below the reservoir or in the main circuit. Each experiment was repeated three times, and the main circuit was allowed to become bubble-free between each experiment. 


\section{Cardiotomy reservoirs and micropore filters tested}

CARDIOTOMY RESERVOIRS

A Polystan HL 282 DF cardiotomy reservoir

B Polystan HL 280 DF cardiotomy reservoir

C Polystan $\mathbf{4 0}$ cardiotomy reservoir

(Albert Browne Ltd, Chancery House, Abbey Gate, Leicester LE4 0AA)

D Bentley Q220 disposable expanded volume cardiotomy reservoir

E Bentley Q120 disposable cardiotomy reservoir

F Bentley Q220F disposable expanded volume cardiotomy reservoir with filter

(Bentley Laboratories Ltd, 50 Mount Street, London W1Y 5RE)

G Travenol 2-litre cardiotomy blood reservoir 5M0391

H Travenol rigid cardiotomy reservoir 5M0305

(Travenol Laboratories, Caxton Way, Thetford, Norfolk IP24 3SE)

I Cobe cardiotomy reservoir 42-301

J Cobe cardiotomy reservoir with Swank filter 42-300

(Cimid Ltd, Barnfield Road, Park Farm Industrial Estate, Folkestone, Kent CT19 5EX)

K Harvey disposable cardiotomy reservoir model H500

(GU Manufacturing Co Ltd, Plympton Street, London NW8 8AB)

L Bromlus cardiotomy suction filter and defoamer (Avon Medicals Ltd, 1649 Pershore Road, Birmingham B30 3DR)

MICROPORE FILTERS

Intersept arterial extracorporeal blood filter

Intersept cardiotomy extracorporeal blood filter (Johnson and Johnson Ltd, 260 Bath Road, Slough, Berks SL1 4EA)

Pall Ultipor blood filter (Pall Biomedical Ltd, Walton Road, Portsmouth PO6 1TD).

\section{Results}

Using a Polystan HL 282 DF cardiotomy reservoir sequential experiments were carried out after collection of blood in the reservoir. This blood was pumped without micropore filtration past the detector head immediately after collection or after it had remained in the reservoir for varying periods. Figure 2 shows the decline in numbers of gaseous microemboli greater than $10 \mu$ in diameter remaining in the blood related to increasing storage time.

The relative speeds of pumps $B$ and $C$ determine the blood/gas volume ratio of the simulated cardiotomy suction blood. The effluent from a Polystan

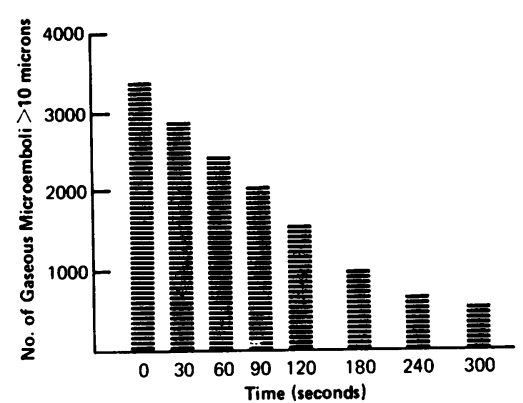

Fig. 2 Numbers of gaseous microemboli $>10$ microns remaining in effluent from Polystan $H L 282 \mathrm{DF}$ cardiotomy reservoir in relation to duration of storage time.

HL 282 DF cardiotomy reservoir showed an in creasing number of gaseous microemboli as the proportion of air in the blood injected into the reservoir increased (Fig. 3).

Using a blood/gas volume ratio of $1 / 2 \cdot \bar{Z}$ in the simulated cardiotomy suction blood a equal volume was successively injected into eaclof of 12 commercially available cardiotomy reser voirs. The effluent was immediately pumped pas the detector head without micropore filtration of after passage through an Ultipor filter. The result? (Fig. 4) showed a wide variation in the ability of the reservoirs to remove gaseous microemboli, bu in all cases performance was improved by using a micropore filter below the reservoir.

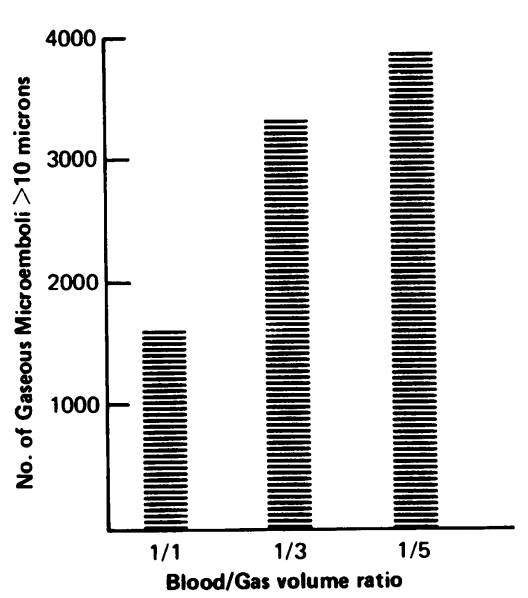

Fig. 3 Numbers of gaseous microemboli $>10$ microng remaining in effluent from Polystan HL 282 DF cardiotomy reservoir in relation to blood/gas volume ratio of aspirated blood. 


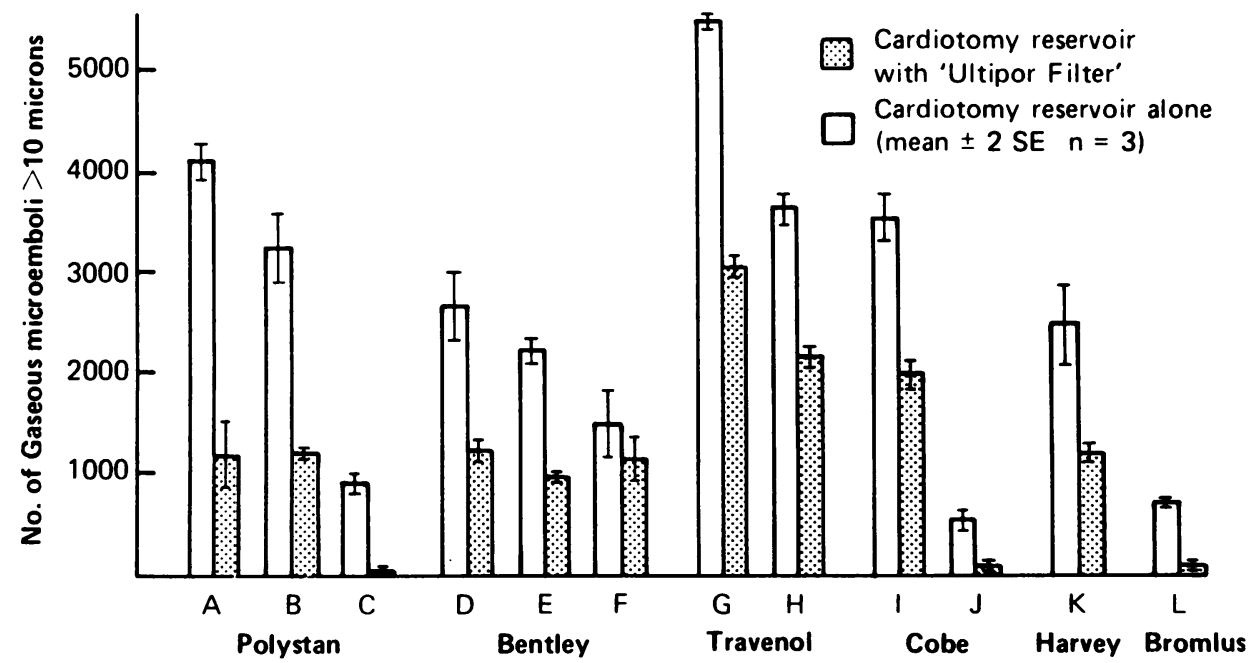

Fig. 4 Comparative numbers of gaseous microemboli $>10$ microns remaining in effluent from various cardiotomy reservoirs with and without filtration by a 40-micron Ultipor filter. Reservoirs type $A-L$ (see text).

When a micropore filter and bypass were inserted into the main circuit the effluent from the cardiotomy reservoir could be discharged directly into this circuit with the detector head applied to the tubing distal to the filter (Fig. 1). In this way the ability of a micropore filter to retain gaseous microemboli when sited in the simulated arterial line could be compared with its efficiency when sited below the cardiotomy reservoir. As the priming volume of the main circuit exceeded 31 and the flow rate of pump $A$ was maintained at $2.51 / \mathrm{min}$ no gaseous microemboli were counted twice, provided the duration of the counting did not exceed one minute. An aneroid manometer was placed in the main circuit and the line pressure distal to the filter was adjusted to $13.4 \mathrm{kPa}$

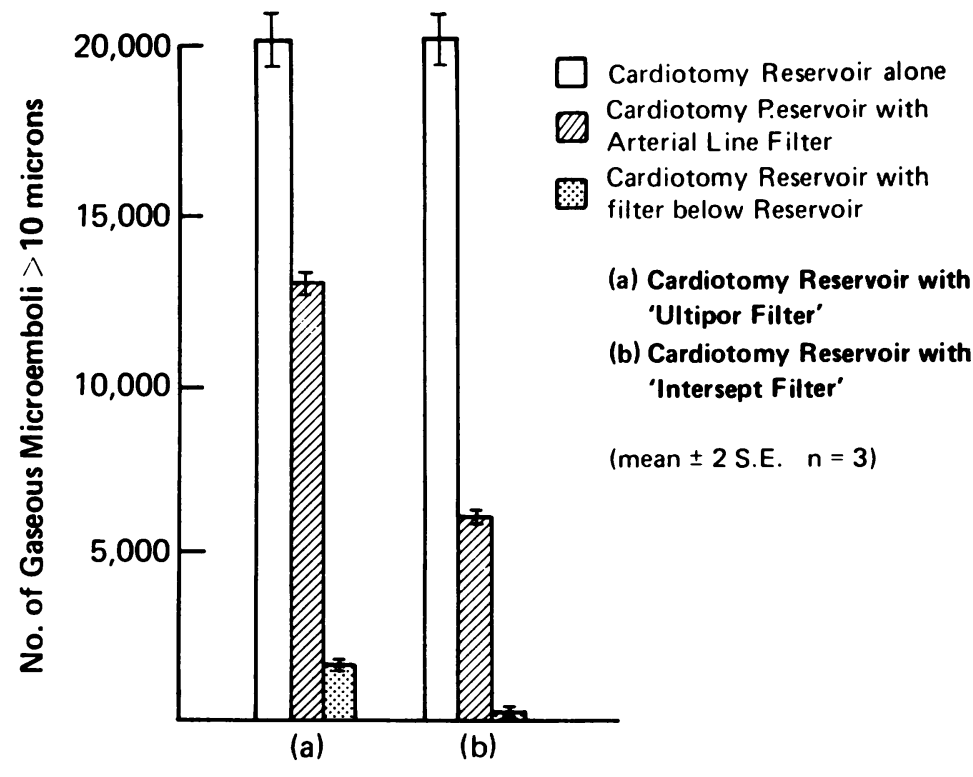

Fig. 5 Comparison of efficiency of micropore filters sited below cardiotomy reservoir and in a simulated arterial line. 
(100 $\mathrm{mmHg})$ by means of a screw clamp. The results (Fig. 5) showed that the numbers of gaseous microemboli from a Polystan HL 282 DF cardiotomy reservoir were reduced by a micropore filter inserted in the arterial line, but a much greater reduction was achieved by inserting the filter below the cardiotomy reservoir. A greater overall reduction in the number of gaseous microemboli was obtained when the $40 \mu$ pore size Ultipor filter was replaced by the $20 \mu$ pore size arterial line and cardiotomy Intersept filters (Table 1).

The insertion of the $20 \mu$ Intersept filter and the $40 \mu$ Ultipor filter in parallel in the main circuit allowed direct comparisons of their efficiency by subjecting them alternately to a standard load of gaseous microemboli from the effluent of a cardiotomy reservoir. In addition, the size profile of the bubbles that passed through the filters could be compared. The results (Table 2) confirmed the greater efficiency of the $20 \mu$ filter. Most gaseous microemboli passing through this filter were in the 10-20 $\mu$ range, while the majority passing through the $40 \mu$ filter were in the $10-30 \mu$ range.

Table 1 Percentage reduction in gaseous microemboli from standard cardiotomy suction using a Polystan HL 282 DF cardiotomy reservoir and two types of micropore filter

\begin{tabular}{lll}
\hline & $\begin{array}{l}\text { Micropore filter } \\
\text { below cardiotomy } \\
\text { reservoir }\end{array}$ & $\begin{array}{l}\text { Cardiotomy reservoir } \\
\text { with micropore filter } \\
\text { in arterial line }\end{array}$ \\
\hline $\begin{array}{l}\text { Intersept filter } \\
\text { (20 micron) }\end{array}$ & $99 \%$ & $68 \%$ \\
$\begin{array}{l}\text { Ultipor filter } \\
\text { (40 micron) }\end{array}$ & $92 \%$ & $48 \%$ \\
\hline
\end{tabular}

Table 2 Size profile of gaseous microemboli detected beyond arterial line filter

\begin{tabular}{lll}
\hline $\begin{array}{l}\text { Bubble size } \\
\text { (microns) }\end{array}$ & 40-micron Ultipor filter & 20 -micron Intersept filter \\
\hline$>10$ & No. $(\%)$ & No. $(\%)$ \\
$10-20$ & $13609(100)$ & $6064(100)$ \\
$21-30$ & $8025(59)$ & $5372(88)$ \\
$31-40$ & $5064(37)$ & $658(11)$ \\
$>40$ & $470(3)$ & $34(1)$ \\
\hline
\end{tabular}

\section{Discussion}

Previous work in this unit has indicated the importance of cardiotomy suction as a source of gaseous microemboli (Gallagher and Pearson,
1973). These emboli are potentially more danger- $\stackrel{\vec{F}}{\rightarrow}$ ous than those originating from a bubble oxygenator because they consist mainly of nitrogen, a relatively insoluble gas. The persistence of $\frac{\bar{\omega}}{\frac{}{2}}$ these microemboli after passage through both the $\stackrel{\mathbb{Q}}{\Omega}$ defoamer of the cardiotomy and the oxygenator indicates their stability.

We show the wide variation in the ability of 12. commercially available cardiotomy reservoirs to $\vec{\omega}$ remove bubbles from aspirated blood and produce $\odot$ an effluent relatively free from gaseous micro- $\vec{x}$ emboli. The design of a reservoir can affect its performance. Some of those tested induced tur $-\omega$ bulence and frothing before admitting blood to $\omega$ the defoamer and also allowed a proportion of the $N$ blood to pass through the reservoir without com-응 ing into contact with the defoaming substance.Other reservoirs, having defoamed the blood, $\subseteq$ allowed it to splash into the storage part of the reservoir. All these factors increase the number $\vec{\theta}$ of gaseous microemboli in the effluent.

A cardiotomy reservoir with improved filtration. characteristics (Solis et al., 1976) needs to be developed, since in the reservoirs tested those that incorporated a $40 \mu$ nylon mesh or Dacron woolo filter performed best. The three Polystan reser- 0 voirs are essentially similar in overall design but $\stackrel{\mathcal{Q}}{\circ}$ show a progressive improvement in efficiency as $\overrightarrow{\vec{B}}$ the pore size of the filter in the storage part of the 3 reservoir is reduced from 180 through 120 to $40 \mu$. The Bentley Q220F reservoir incorporating a $27 \mu$. filter did not perform as well as expected. Not only did this unit suffer from splashing of the음 defoamed blood but it induced turbulence at the blood inlet ports.

An analysis of the design features of the reservoirs, assessed by correlation of their in-vitroo performance with the overall configuration of the reservoir, type of defoamer, and pore size of theo incorporated filter material suggests that optimal $>$ efficiency can be achieved by direct injection of음 aspirated blood into the defoaming substance and filtration by either Dacron wool or $40 \mu$ nylon ${ }^{\mathrm{N}}$ mesh. Defoamed and filtered blood should not be 0 allowed to fall freely into the storage part of the w reservoir.

Alterations in perfusion technique will influence the performance of the cardiotomy reservoirs. If the blood is stored in the reservoir for as long aș possible within the confines of an adequate levelo in the oxygenator, not only will maintenance of $a \overrightarrow{0}$ higher level reduce splashing of the defoamed blood but gaseous microemboli will have mores time to settle out. The greater the proportion of air to blood in the aspirate from the open heart and pericardium the more difficult it is for theo 
cardiotomy reservoirs to remove gaseous microemboli completely. The speed of the suction pumps should be monitored continuously to allow as low an admixture of air with the blood as is compatible with the surgical technique.

Filtration of blood after passage through the cardiotomy reservoir reduces further the numbers of gaseous microemboli. The size and number of gaseous microemboli remaining is related to the pore size of the micropore filter used. However, microfiltration is only a partial solution to a problem best solved by avoiding factors responsible for the formation of microemboli (Wright and Dunn, 1975) and by choosing the most efficient cardiotomy reservoir. A simulated arterial line micropore filter is not as effective in removing gaseous microemboli as the same type of filter sited below the cardiotomy reservoir. During clinical perfusion, defoamed blood is returned to the oxygenator at a low flow rate by gravity, but when the filter is placed in the arterial line it is subjected to a much greater flow of blood. During the experiments the arterial line filter released gaseous microemboli into the main circuit when it was tapped. Considerable care was needed during priming of the filter to ensure that no gas was trapped in the filter medium.

The TM8 Microbubble Activity Monitor is calibrated by the manufacturer using a technique of releasing single bubbles of known size into a stream of liquid flowing past the transducer head. The bubbles are electrolytically generated, and their size is measured by microscopy. This calibration is confirmed in the experiments by counting the numbers of bubbles that passed through filters with different pore sizes: only $1 \%$ of bubbles passing through the $40 \mu$ filter exceeded $40 \mu$ in diameter, and only $12 \%$ of those passing through the $20 \mu$ filter exceeded $20 \mu$ in diameter.

No reference has been made to the ability of the cardiotomy reservoirs and filters tested to deal with non-gaseous microemboli. Other workers have evaluated various devices used in the cardiotomy reservoir system in this respect (Loop et al., 1976; Solis et al., 1976). We have not tested the long-term comparative efficiency of the reservoirs and filters.

Cerebral damage after open-heart surgery has a multifactorial aetiology (Lancet, 1975). Constant vigilance should be exercised in eliminating all sources of gaseous microemboli originating in the oxygenator and cardiotomy reservoir system. Probably by improving perfusion technique using oxygenators that do not generate gaseous microemboli (Karlson et al., 1974; Siderys et al., 1975) and incorporating an efficient cardiotomy reservoir with a $20 \mu$ filter into the cardiopulmonary bypass circuit the number of gaseous microemboli delivered to the patient will be substantially reduced.

We thank Mr. E. M. Cole of Technique Laboratories for the loan of the Microbubble Activity Monitor and the various firms who donated reservoirs and filters for assessment.

\section{References}

Aberg, T. (1974). Effect of open-heart surgery on intellectual function. Scandinavian Journal of Thoracic and Cardiovascular Surgery, Supplement 15.

Aberg, T., and Kihlgren, M. (1977). Cerebral protection during open-heart surgery. Thorax, 32, 525-533.

Aguilar, M. J., Gerbode, F., and Hill, J. D. (1971). Neuropathologic complications of cardiac surgery. Journal of Thoracic and Cardiovascular Surgery, 61, 676-685.

Branthwaite, M. A. (1975). Prevention of neurological damage during open-heart surgery. Thorax, 30, 258261.

Brennan, R. W., Patterson, R. H., and Kessler, J. (1971). Cerebral blood flow and metabolism during cardiopulmonary bypass. Neurology, 21, 665-672.

Clark, D. K., and Reed, C. C. (1974). Extracorporeal filtration of blood. Journal of Extracorporeal Technology, 6, 185-194.

Gallagher, E. G., and Pearson, D. T. (1973). Ultrasonic identification of sources of gaseous microemboli during open-heart surgery. Thorax, 28, 295305.

Hill, J. D., Osborn, J. J., and Swank, R. L. (1970). Experience using a new Dacron wool filter during extracorporeal circulation. Archives of Surgery, 101, 649-652.

Karlson, K. E., Murphy, W. R., Kakvan, M., Anthony, P., Cooper, G. N., Richardson, P. D., and Galletti, P. M. (1974). Total cardiopulmonary bypass with a new microporous Teflon membrane oxygenator. Surgery, 76, 935-945.

Lancet (1975). Editorial. Brain damage after openheart surgery. Lancet, 2, 399-400.

Loop, F. D., Szabo, J., Rowlinson, R. D., and Urbanek, K. (1976). Events related to microembolism during extracorporeal perfusion in man. Effectiveness of in-line filtration recorded by ultrasound. Annals of Thoracic Surgery, 21, 412-420.

Patterson, R. H., and Kessler, J. (1969). Microemboli during cardiopulmonary bypass detected by ultrasound. Surgery, Gynecology and Obstetrics, 129, 505-510.

Siderys, H., Herod, G. T., Halbrook, H., Pittman, J. N., Rubush, J., Kasebaker, V., and Berry, G. R. (1975). A comparison of membrane and bubble oxygenation as used in cardiopulmonary bypass in patients. Journal of Thoracic and Cardiovascular Surgery, 69, 708-712. 
Solis, R. T., Noon, G. P., Beall, A. C., and De Bakey, M. E. (1974). Particulate microembolism during cardiac operation. Annals of Thoracic Surgery, 17, 332344.

Solis, R. T., Scott, M. A., Kennedy, P. S., and Wilson, R. K. (1976). Filtration of cardiotomy reservoir blood. Journal of Extracorporeal Technology, 8, 69-72.

Tufo, H. M., Ostfeld, A. M., and Shekelle, R. (1970). Central nervous system dysfunction following openheart surgery. Journal of the American Medical Association, 212, 1333-1340.

Wright, G., and Dunn, W. E. (1975). Brain damage $\underset{\vec{\rho}}{\vec{\rho}}$ during extracorporeal circulation for open-heart $\overline{0}$ surgery. Journal of Cardiovascular Technology, 2, $36-41$.

Wright, G., and Sanderson, J. M. (1972). Brain damage $\underset{\mathbb{D}}{\overparen{D}}$ and mortality in dogs following pulsatile and non- $\varrho$ pulsatile blood flows in extracorporeal circulation. \&ै Thorax, 27, 738-747.

Requests for reprints to: Dr. D. T. Pearson, Regional Cardiothoracic Centre, Freeman Hospital, Newcastle upon Tyne NE7 7DN, UK. 